\title{
Influência da velocidade de circulação do leite na adesão de Pseudomonas aeruginosa sobre aço inoxidável
}

\author{
The speed of milk circulation influences the adhesion of Pseudomonas aeruginosa on stainless steel
}

\author{
Hamilton Mendes de FIGUEIREDO ${ }^{4 \star}$, Nelio Jose de ANDRADE ${ }^{1}$, \\ Eliana Ferreira OZELA ${ }^{3}$, Gundisalvo Piratoba MORALES ${ }^{2}$
}

\begin{abstract}
Resumo
A influência da velocidade de circulação do leite na adesão bacteriana de Pseudomonas aeruginosa foi avaliada em teste de uso simulado por meio de um modelo de circuito de processamento de leite. O circuito é composto por uma tubulação de aço inoxidável AISI 304, com $1,9 \mathrm{~cm}$ de diâmetro e 5,8 m de comprimento, além de um tanque de $25 \mathrm{~L}$, utilizado como reservatório do produto e das soluções sanitizantes. O reservatório foi acoplado a uma bomba centrífuga de $1 \frac{1}{2} \mathrm{HP}$, para impulsionar o alimento ou soluções de higienização pelo sistema equipado com cupons de prova em aço inoxidável nas formas cilíndrica, cotovelo $90^{\circ} \mathrm{e}$ T. As velocidades de circulação foram de $0,5,1,0$ e $1,5 \mathrm{~m} . \mathrm{s}^{-1}$, correspondentes a fluxo turbulento com número de Reynolds de 14.000, 28.000 e 42.000, respectivamente. Quando se utilizou velocidade de $0,5 \mathrm{~m} . \mathrm{s}^{-1}$, permaneceram aderidas à superfície $10,7 \%$ das células. Já nas velocidades e $1,0 \mathrm{e} 1,5 \mathrm{~m} . \mathrm{s}^{-1}$ as porcentagens de adesão foram de 5,36 e 4,9\%, respectivamente, o que demonstra uma menor remoção de células aderidas à medida que o fluxo diminui, permitindo assim que mais células permaneçam aderidas na linha de produção, o que pode favorecer a formação de biofilmes.
\end{abstract}

Palavras-chave: adesão bacteriana; biofilme; leite.

\begin{abstract}
The influence of the flow milk circulation in the bacterial adhesion of Pseudomonas aeruginosa was evaluated by simulation tests through a circuit model of milk processing. The circuit is composed of a tubulation of stainless steel AISI 304 , with $1.9 \mathrm{~cm}$ of diameter, $5.8 \mathrm{~m}$ of length and a tank of $25 \mathrm{~L}$ used as the reservoir of the product and sanitizer solutions. The reservoir was coupled to a centrifugal bomb of $1 / 2 \mathrm{HP}$ to impel the food or sanitizer solutions for the system equipped with $90^{\circ}$ and $\mathrm{T}$ cylindrical stainless steel specimens. The speed of circulation values were $0.5,1.0$ and $1.5 \mathrm{~m} . \mathrm{s}^{-1}$, corresponding to turbulent flow with number of Reynolds 14.000, 28.000 and 42.000, respectively. When flow of $0.5 \mathrm{~m} . \mathrm{s}^{-1}$ was used $10.7 \%$ the cells remained adhered, however at the speed values of 1.0 and $1.5 \mathrm{~m} . \mathrm{s}^{-1}$ the adhesion percentages were 5.36 and $4.9 \%$, respectively. These findings indicate a lower removal rate of adhered cells as flow decreases allowing higher number of bacteria to adhere to the production line, which can favor the biofilm formation.

Keywords: bacterial adherence; biofilm; milk.
\end{abstract}

\section{Introdução}

Apesar dos métodos de higienização aplicados na indústria serem em tese bastante eficientes, há casos em que a higienização realizada deficientemente não remove microrganismos e sujidades, possibilitando a adesão de microrganismos em equipamentos e utensílios. Uma vez que esses microrganismos estejam aderidos ou formem biofilmes haverá resistência à remoção pelos processos de sanitização ao mesmo tempo em que células serão liberadas continuamente para o alimento (SHARMA; ANAND, 2002; BESTER et al., 2005; LELIEVELD; MOSTER; HOLAH, 2005).

Cerca de $99 \%$ de todas as bactérias em ambiente natural estão em biofilmes (DALTON; MARCH, 1998) que consistem de microrganismos aderidos a uma superfície auxiliados por substâncias poliméricas extracelulares (COSTERTON et al., 1994;
DENYER; GORMAN; SUSSMAN, 1993; STEWART et al., 2000). Outra definição estabelece que o biofilme é a agregação de células microbianas, crescendo e se multiplicando em uma superfície, sendo essa agregação, promovida por substâncias poliméricas extracelulares produzidas pelos próprios microrganismos (FLINT; BREMER; BROOKS, 1997).

Diversos pesquisadores têm formulado teorias com a finalidade de explicar como ocorre a adesão do microrganismo a uma superfície (MOSTELLER; BISHOP, 1993; ZOTTOLA; SASAHARA, 1994).

Após o contato inicial com a superfície, os microrganismos iniciam a produção de exopolissacarídeos que podem ser observados por microscopia eletrônica ou de força atômica (ANDRADE, 2008). Essas substâncias tornam-se mais densas

Recebido para publicação em 21/3/2007

Aceito para publicação em 7/7/2009 (002410)

${ }^{1}$ Departamento de Tecnologia de Alimentos, Universidade Federal de Viçosa, UFV, CEP 36570000, Viçosa - MG, Brasil

2 Departamento de Agroindústria, Universidade Estadual do Pará, Belém - PA, Brasil

3 Departamento de Farmácia, Universidade Federal do Pará, Belém - PA, Brasil

${ }^{4}$ Departamento de Nutrição, Universidade Federal do Pará, Belém - PA, Brasil, E-mail: hamiltonmendes1@hotmail.com

${ }^{*}$ A quem a correspondência deve ser enviada 
com o tempo, levando à formação da matriz do biofilme. A produção de exopolissacarídeos aumenta com a adesão da bactéria à superfície (KUMAR; ANAND, 1998; BOWER; McGUIRE; DAESCHEL, 1996).

Vários fatores afetam o processo de adesão bacteriana e a formação de biofilmes. Dentre eles, encontram-se os genotípicos, os termodinâmicos e os ambientais. Genes codificam a capacidade do microrganismo em produzir exopolissacarídeos ou a presença de flagelo e fímbria que auxiliam na adesão. Hidrofobicidade e carga elétrica têm um papel importante no processo de adesão bacteriana (HOOD; ZOTTOLA, 1995). Também participam ativamente do processo, o tempo, a temperatura, o $\mathrm{pH}$, a presença de substâncias alcoólicas (HERALD; ZOTTOLA, 1988; STONE; ZOTTOLA, 1985, GRAVESEN; LEKKAS; KNOCHEL, 2005) e o fluxo das soluções de limpeza e dos alimentos sobre as superfícies.

Esta pesquisa estudou a influência da velocidade de circulação do leite na adesão de Pseudomonas aeruginosa por meio de um sistema-modelo. A escolha desta bactéria deve-se ao fato de ser uma das bactérias mais atuantes no processo de deterioração do leite e frequentemente ser encontrada em grande número nos equipamentos antes de serem higienizados.

\section{Material e métodos}

\subsection{Microrganismo}

Pseudomonas aeruginosa ATCC 15442 foi usada no experimento. Após armazenamento a $-10^{\circ} \mathrm{C}$, o microrganismo foi ativado em $10 \mathrm{~mL}$ de caldo nutriente, sendo em seguida incubado a $35^{\circ} \mathrm{C}$ por 12 horas. Após esse período, houve uma repicagem para o mesmo meio, com reincubação a $35^{\circ} \mathrm{C}$, por 10 horas.

\subsection{Processo de adesão e quantificação da população bacteriana aderida à tubulação}

Decorrida a ativação, foi feita a inoculação de $400 \mathrm{~mL}$ de leite esterilizado $\left(121{ }^{\circ} \mathrm{C}\right.$ por 15 minutos) utilizando-se P. aeruginosa. A inoculação foi realizada de modo a obter-se uma contagem aproximada de $1 \times 10^{6}$ UFC. $\mathrm{mL}^{-1}$ determinada por plaqueamento em ágar para contagem padrão (PCA) a $35^{\circ} \mathrm{C}$ por 48 horas.

Foi utilizado um modelo de circuito de processamento de leite em aço inoxidável (Figura 1), constituído por uma tubulação de $3 / 4$ de polegada de diâmetro interno e comprimento total de $5,8 \mathrm{~m}$, por onde circulou o leite a partir de um tanque de $25 \mathrm{~L}$, que foi utilizado como reservatório. Em pontos específicos da tubulação foram instalados cupons de prova em aço inoxidável com formatos de cotovelo $90^{\circ}$, " $\mathrm{T}$ " e cilíndricos. As áreas superficiais internas dos cupons de prova eram: $108,06 \mathrm{~cm}^{2}$ para cupons tipo " $T$ ", $52,74 \mathrm{~cm}^{2}$ para cupons em cotovelo $\left(90^{\circ}\right)$ e $84,69 \mathrm{~cm}^{2}$ para cupons cilíndricos.

Para permitir a adesão, o leite inoculado foi utilizado para encher os cupons de prova de aço inoxidável $(27 \mathrm{~mL}$ de leite no cupom em cotovelo $90^{\circ}, 57 \mathrm{~mL}$ no cupom em "T" e $49 \mathrm{~mL}$ no cupom cilíndrico), os quais foram incubados a $18^{\circ} \mathrm{C}$. O tempo

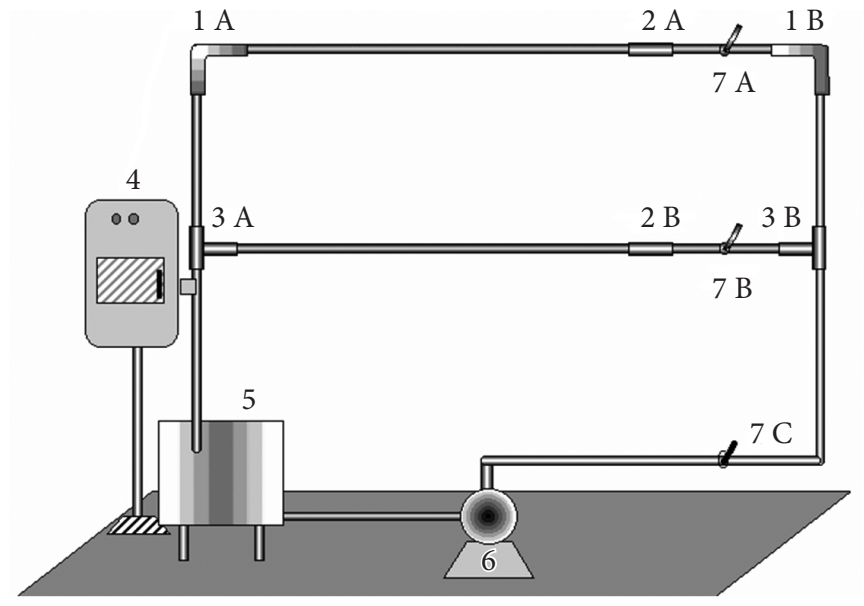

Figura 1. Equipamento modelo de linha de processamento de leite ( 1 - Cupom de prova tipo cotovelo $90^{\circ} ; 2$ - Cupom de prova cilíndrico; 3 - Cupom de prova "T"; 4 - Controle liga/desliga; 5 - Reservatório de leite; 6 - Bomba centrífuga; 7 - Válvulas tipo borboleta).

de incubação foi de 12 horas. Após esse período, amostras do leite do interior dos cupons foram plaqueadas em ágar para contagem padrão (PCA) e o restante descartado. Dessa maneira pôde-se conhecer o número de bactérias em suspensão no leite (UFC. $\mathrm{mL}^{-1}$ ). Em seguida, o leite esterilizado foi adicionado aos cupons de prova, mantido ali por dois minutos e depois novamente descartado, para eliminação de células planctônicas ou fracamente aderidas aos cupons. Três cupons de prova (1B, $2 \mathrm{~B}$ e $3 \mathrm{~B}$ ) foram mantidos com as bactérias aderidas, enquanto que os outros três $(1 \mathrm{~A}, 2 \mathrm{~A}$ e $3 \mathrm{~A})$ foram preenchidos com solução de citrato de sódio a $2 \%(20 \mathrm{~mL}$ no cupom em curva, $30 \mathrm{~mL}$ no cupom cilíndrico e $40 \mathrm{~mL}$ no cupom tipo “T”), rinsados sob agitação manual por 15 minutos e, então, foi feito o plaqueamento da solução de rinsagem, com o objetivo de se conhecer o número de bactérias aderidas a estes cupons antes da circulação do leite. Essa menor quantidade da solução de rinsagem em relação ao leite foi para permitir uma melhor agitação do líquido dentro dos cupons a fim de remover as bactérias aderidas, o que não seria possível se o cupom estivesse totalmente cheio. O restante da solução de citrato de sódio foi descartado e os três cupons foram tratados com uma solução de hipoclorito de sódio contento $300 \mathrm{mg} . \mathrm{L}^{-1}$ de cloro residual livre por 5 minutos, sendo, em seguida, lavados por três vezes em água destilada para serem subsequentemente usados no equipamento. Os seis cupons de prova foram conectados ao equipamento modelo da linha de processamento de leite. Ao reservatório do equipamento foram adicionados $10 \mathrm{~L} \mathrm{de}$ leite esterilizado ( $121^{\circ} \mathrm{C}$ por 15 minutos), que circulou por 10 minutos a $0,5,1,0$ e $1,5 \mathrm{~m} \cdot \mathrm{s}^{-1} \mathrm{em}$ temperatura média de $15^{\circ} \mathrm{C}$. Para manter a velocidade desejada, manuseou-se a válvula $7 \mathrm{C}$ de modo a obter-se uma vazão duas vezes maior que a desejada. A válvula $7 \mathrm{~A}$ ficou totalmente aberta e a $7 \mathrm{~B}$ foi aberta até o ponto em que permitia a distribuição do leite em quantidades iguais entre as válvulas 7B e 7A. 


\subsection{Procedimento de limpeza do equipamento}

Após a utilização, o modelo foi novamente montado, recolocando-se os cupons em seus devidos lugares, e, em seguida, submetido à higienização, utilizando-se vazão de $1,5 \mathrm{~m} \cdot \mathrm{s}^{-1}$, que constou das seguintes etapas:

a) Pré-enxágue com água à temperatura ambiente por 5 minutos;

b) Limpeza com hidróxido de sódio a $1 \%$ de alcalinidade cáustica a $80^{\circ} \mathrm{C}$ por 20 minutos;

c) Enxágue até remoção do hidróxido de sódio, o que foi constatado através de reação com fenolftaleína;

d) Lavagem ácida com solução de ácido nítrico a $0,5 \%$ a $70^{\circ} \mathrm{C}$ durante 10 minutos;

e) Enxágue até remoção do ácido nítrico, constatada pela reação com alaranjado de metila;

f) Sanificação com solução de hipoclorito de sódio a $100 \mathrm{mg} . \mathrm{L}^{-1}$ de cloro residual livre, em $\mathrm{pH}$ 10, à temperatura na faixa de 20 a $25^{\circ} \mathrm{C}$;

g) Enxágue até remoção do hipoclorito, constatada por reação com solução de ortotoluidina;

h) Lavagem dos cupons de prova, após cada experimento, com detergente enzimático "Tergazyme" e escovação interna;

i) Desmontagem das partes e esterilização a $121{ }^{\circ} \mathrm{C}$ por 15 minutos a cada três procedimentos de adesão utilizando o mesmo microrganismo; e

j) Esterilização a $121{ }^{\circ} \mathrm{C}$ por 15 minutos dos cupons de prova antes de cada uso.

Para determinar a vazão em que as velocidades de 0,5 , 1,0 e $1,5 \mathrm{~m} \cdot \mathrm{s}^{-1}$ foram atingidas foi realizado o seguinte cálculo (Equação 1):

$X=\frac{Y(m / s)}{\pi(R)^{2}}$

em que $\mathrm{Y}=$ corresponde à velocidade que se deseja obter (metro/ segundo); e $\mathrm{R}$ = corresponde ao raio da tubulação.

A fim de se conhecer o número de bactérias removidas após a circulação do leite no modelo decorrido o período de circulação do leite, os cupons de prova $1 \mathrm{~B}, 2 \mathrm{~B}$ e $3 \mathrm{~B}$, não rinsados anteriormente, foram retirados do sistema, rinsados com solução de citrato de sódio de maneira semelhante à anterior e as soluções de rinsagem foram plaqueadas após diluições adequadas.

Os plaqueamentos foram feitos em duplicata com três repetições, utilizando ágar para contagem padrão e a incubação foi a $35^{\circ} \mathrm{C}$ por 48 horas.

Quando necessário, foi calculado o número de Reynolds utilizando-se da Equação 2:

$\operatorname{Re}=\frac{\rho V d}{\mu}$ em que $\rho=$ massa específica do fluido $\left(\mathrm{kg} / \mathrm{m}^{3}\right) ; \mathrm{V}=$ velocidade de escoamento $\left(\mathrm{m} \cdot \mathrm{s}^{-1}\right) ; \mathrm{d}=$ diâmetro da tubulação $(\mathrm{m})$; e $\mu=$ viscosidade do fluido $(\mathrm{kg} / \mathrm{m} . \mathrm{s})$.

\section{Resultados e discussão}

\subsection{Adesão sob condições estáticas}

Após 12 horas de incubação a $18{ }^{\circ} \mathrm{C}$, a contagem de células planctônicas mais as células sésseis de $P$. aeruginosa no leite dentro dos cupons $1 \mathrm{~A}, 2 \mathrm{~A}$ e $3 \mathrm{~A}$ atingiu $6,86 \log$ UFC. $\mathrm{mL}^{-1}$ (Tabela 1), correspondendo a um aumento médio de 0,9 ciclo log na população dos microrganismos em relação à população original $\left(5,97 \log \mathrm{UFC} \cdot \mathrm{mL}^{-1}\right)$. Desse total, $5,83 \%$ estavam na forma séssil, ou seja, estavam aderidos à superfície de aço inoxidável, equivalentes a 5,23 log UFC.cm ${ }^{-2}$. Esse número de microrganismos encontrava-se aderido nos cupons de prova antes de serem acoplados ao sistema modelo.

O resultado mostra que apenas uma parte das células se torna séssil. Este fato é de fácil entendimento uma vez que inúmeros fatores afetam o processo de adesão bacteriana às superfícies. Sabe-se que fatores genotípicos, como a expressão dos genes que codificam a presença de flagelos, fímbria e pili e a produção de exopolissacarídeos, ajudam no processo de adesão. As interações entre micro-organismos como competição, cooperação e predação estão envolvidas no processo (KUMAR; ANAND, 1998).

\subsection{Adesão sob fluxos diferentes}

Na Figura 2, é mostrado o efeito da velocidade do leite na remoção de células aderidas às superfícies das tubulações de aço inoxidável, no sistema-modelo. Quando a velocidade de

Tabela 1. Log UFC.mL $\mathrm{mL}^{-1}$ e log de UFC.cm ${ }^{-2}$ de células de Pseudomonas aeruginosa suspensas no leite e aderidas nos cupons de prova $1 \mathrm{~A}, 2 \mathrm{~A}$ e $3 \mathrm{~A}$, desenvolvidas a $18^{\circ} \mathrm{C}$.

\begin{tabular}{ccc}
\hline $\begin{array}{c}\text { Log UF.mL } \\
\text { no tempo } 0\end{array}$ & $\begin{array}{c}\text { Log UFC. } \mathrm{mL}^{-1} \text { no leite } \\
\text { após } 12 \text { horas }\end{array}$ & $\begin{array}{c}\text { Log UFC. } \mathrm{cm}^{-2} \text { após } \\
12 \text { horas de contato }\end{array}$ \\
\hline 5,97 & 6,86 & 5,23 \\
\hline
\end{tabular}

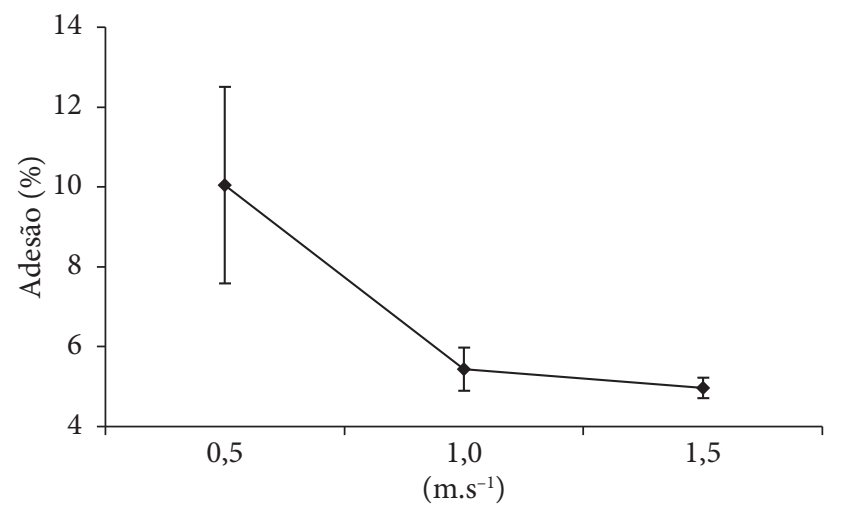

Figura 2. Porcentagem de células de Pseudomonas aeruginosa que permanecem aderidas em cupons de aço inoxidável, independente do tipo de cupom, após a circulação do leite por 10 minutos a $15^{\circ} \mathrm{C}$ em diferentes velocidades. 
circulação foi de $0,5 \mathrm{~m} \cdot \mathrm{s}^{-1}$, permaneceram aderidas aos cupons de prova $10,7 \%$ das células, o que equivale a uma diminuição de $1,6 \times 10^{5}$ UFC. $\mathrm{cm}^{-2}$ para $1,7 \times 10^{4}$ UFC.cm ${ }^{-2}$. Para a velocidade de $1,0 \mathrm{~m} \cdot \mathrm{s}^{-1}$, a porcentagem de bactérias que resistiram ao fluxo foi de $5,36 \%$, o que fez com que o número de bactérias aderidas mudasse de $3,2 \times 10^{5}$ UFC.cm ${ }^{-2}$ para $1,7 \times 10^{4}$ UFC. $\mathrm{m}^{-2}$. A velocidade de $1,5 \mathrm{~m} \cdot \mathrm{s}^{-1}$ permitiu que $4,9 \%$ das bactérias permanecessem aderidas, alterando o número de bactérias de $2,7 \times 10^{5}$ UFC.cm ${ }^{-2}$ para $1,3 \times 10^{4}$ UFC.cm ${ }^{-2}$, sendo o restante das células liberadas para o leite.

Usando o leite como o fluido circulante, esta pesquisa mostra que, à medida que a velocidade é aumentada, ocorre uma maior remoção de microrganismos das superfícies. É conhecimento bem estabelecido que a velocidade de circulação de alimentos ou de soluções de higienização, como detergentes e sanitizantes, além do $\mathrm{pH}$ dos alimentos, do tempo e temperatura, são os fatores de adesão bacteriana mais facilmente controlados na indústria de alimentos.

As informações extraídas do experimento podem ser úteis, particularmente com relação ao fluxo do alimento e das soluções de higienização de equipamentos e utensílios. A velocidade com que o leite deve ser bombeado, antes e depois do processamento, é muito importante não apenas em relação às características químicas do alimento, mas também por questões microbiológicas. Sugere-se normalmente que a velocidade de circulação do leite esteja entre 0,8 e $1,0 \mathrm{~m} \cdot \mathrm{s}^{-1}$ (KNIPSCHILDT, 1986).

Observou-se no estudo que, quando a velocidade de circulação do leite é de $0,5 \mathrm{~m} \cdot \mathrm{s}^{-1}$, ocorre um grande número de células aderidas nas tubulações (Figura 2), o que pode resultar em possíveis problemas de formação de biofilmes, se a higienização não for efetuada corretamente.

Considerando-se que determinados patógenos podem representar perigo à saúde, ainda que em concentrações baixas como $10^{3} \mathrm{UFC} \cdot \mathrm{mL}^{-1}$, pode-se concluir que mesmo a presença de poucas células no início do processo pode representar um risco crescente à saúde do consumidor ao longo do período de produção. A célula bacteriana aderida cresce e se divide usando os nutrientes presentes no filme condicionante e no meio circundante (KUMAR; ANAND, 1998). Isso leva à formação de microcolônias que se espalham sobre a superfície. Durante esse período, as células aderidas produzem polímeros adicionais que ajudam na adesão das células à superfície.

Outra questão a considerar é que, se a velocidade de bombeamento for demasiadamente alta e a tubulação estiver contaminada, haverá inicialmente uma grande contaminação do leite em razão da transferência de bactérias aderidas para o fluido (Figura 2).

As velocidades utilizadas no experimento resultaram em fluxos que podem ser caracterizados como turbulentos, já que foram determinados os valores de número de Reynolds de 4700, 9400 e 14100 para as velocidades de 0,5, 1,0 e 1,5 m.s ${ }^{-1}$, respectivamente. No entanto, os resultados mostram, no que se refere à adesão bacteriana, não haver diferença relevante entre as velocidades de $1 \mathrm{e} 1,5 \mathrm{~m} \cdot \mathrm{s}^{-1}$.
Tabela 2. Porcentagem de $P$. aeruginosa que permaneceram aderidas aos diferentes tipos de cupons de aço inoxidável submetidos a velocidades de $0,5,1,0$ e $1,5 \mathrm{~m} \cdot \mathrm{s}^{-1}$ durante 10 minutos em modelo de linha de processamento de leite, utilizando-se como fluido o leite integral a $15^{\circ} \mathrm{C}$.

\begin{tabular}{|c|c|c|c|}
\hline & & Adesão (\%) & \\
\hline $\begin{array}{l}\text { Velocidades } \\
\left(\mathrm{m} \cdot \mathrm{s}^{-1}\right)\end{array}$ & $\begin{array}{l}\text { Cupom } \\
\text { cilíndrico }\end{array}$ & $\begin{array}{c}\text { Cupom em } \\
\text { cotovelo }\end{array}$ & $\begin{array}{c}\text { Cupom tipo } \\
\text { "T" }\end{array}$ \\
\hline 0,5 & 18,0 & 8,9 & 8,6 \\
\hline 1,0 & 11,9 & 4,4 & 2,6 \\
\hline 1,5 & 10,1 & 4,5 & 1,4 \\
\hline
\end{tabular}

Em relação à circulação de soluções de higienização, os resultados do experimento confirmam as recomendações técnicas de se usar velocidades maiores que aquelas do processamento do leite para se obter superfícies com melhor qualidade microbiológica para o contato com os alimentos. Velocidades iguais ou superiores a $1,5 \mathrm{~m} \cdot \mathrm{s}^{-1}$ são frequentemente utilizadas em processos de higienização. Velocidades inferiores podem comprometer a qualidade da higienização, e a inobservância dessa recomendação pode permitir que grande número de bactérias permaneça aderido à superfície.

Observa-se que há uma tendência a permanecer um maior número de bactérias sésseis no cupom cilíndrico, independente da velocidade de bombeamento do leite (Tabela 2). Porém, deve-se ressaltar que, à medida que o fluxo do leite aumenta, o número de células aderidas diminui. Assim, foram constatadas porcentagens de adesão, no cupom cilíndrico, de $18,0,11,9$ e $10,1 \%$ para as velocidades de $0,5,1,0$ e $1,5 \mathrm{~m} \cdot \mathrm{s}^{-1}$, respectivamente.

A menor adesão foi no cupom tipo " $\mathrm{T}$ " em todas as velocidades de bombeamento utilizadas. Isso equivale a $8,6 \%$ para $0,5 \mathrm{~m} \cdot \mathrm{s}^{-1}, 2,6 \%$ para $1 \mathrm{~m} \cdot \mathrm{s}^{-1} \mathrm{e} 1,4 \%$ para $1,5 \mathrm{~m} \cdot \mathrm{s}^{-1}$.

Em pesquisa realizada utilizando adesão de Enterococcus faecium em cupons de aço inoxidável e depois circulando água a $1,5 \mathrm{~m} \cdot \mathrm{s}^{-1}$, foi obtida uma redução decimal de 0,52 no número de células aderidas (MELLO, 1997), enquanto que nesta pesquisa houve uma redução decimal de 1,3, utilizando o leite a $1,5 \mathrm{~m} \cdot \mathrm{s}^{-1}$.

\section{Conclusões}

A velocidade de circulação do leite influenciou a adesão de microrganismos no sistema-modelo. Verificou-se que a $0,5 \mathrm{~m} \cdot \mathrm{s}^{-1}$ permanecem aderidas aos cupons de prova $10,7 \%$ das células, enquanto que nas velocidades de $1,0 \mathrm{e} 1,5 \mathrm{~m} \cdot \mathrm{s}^{-1}$ as porcentagens de adesão foram de 5,36 e 4,9\%, respectivamente. Isso mostra uma tendência de que um maior número de células permaneça aderido à medida que fluxos mais baixos forem utilizados na linha de produção. Portanto conclui-se que, em relação aos fatores estudados neste experimento, a melhor velocidade a ser utilizada é a de $1,0 \mathrm{~m} \cdot \mathrm{s}^{-1}$, já que a literatura sugere, por questões químicas, uma velocidade de 0,8 a $1,0 \mathrm{~m} \cdot \mathrm{s}^{-1}$. 


\section{Referências bibliográficas}

ANDRADE, N. J. Higiene na indústria de alimentos. São Paulo: Varela, 2008. 400 p.

BESTER, E. et al. Planktonic-Cell Yield of a Pseudomonad Biofilm. Applied and Environmental Microbiology, v. 71, n. 12, p. 7792-7798, 2005.

BOWER, C. K.; McGUIRE, J.; DAESCHEL, M. A. The adhesion and detachment of bacteria and spores on food-contact surfaces. Trends in Food Science \& Technology, v. 7, May, p.152-157, 1996.

COSTERTON, J. W. et al. Biofilms, the customized microniche. Journal of Bacteriology. v. 176, n. 8, p. 2137-2142, 1994.

DALTON, H. M.; MARCH, P. E. Molecular genetics of bacterial attachment and biofouling. Current Opinion in Biotechnology, v. 9, June, p. 252-255, 1998.

DENYER, S. P.; GORMAN, S. P.; SUSSMAN, M. Microbial biofilms: formation and control. Londres: Blackwell Scientific Publications, 1993. p. 18

FLINT, S. H.; BREMER, P. J.; BROOKS, J. D. Biofilms in dairy manufacturing plant: description, current concerns and methods of control. Biofouling, v. 11, n. 1, p. 81-87, 1997.

GRAVESEN, A.; LEKKAS, C.; KNOCHEL, S. Surface Attachment of Listeria monocytogenes is induced by sublethal concentrations of alcohol at low temperatures. Applied and Environmental Microbiology, v. 71, n. 9, p. 5601-5603, 2005.

HERALD, P. J.; ZOTTOLA, E. A. Scanning electron microscopic examination of Yersinia enterocolitica attached to sainless steel at selected temperatures and $\mathrm{pH}$ values. Journal Food Protection, v. 51, n. 6 , p. $445-448,1988$.
HOOD, S.; ZOTTOLA, E. A. Biofilms in food processing. Food Control, v. 6, n. 1, p. 8-18, 1995.

KNIPSCHILDT, M. E. Drying of milk and milk products. In: ROBINSON, R. K. Modern dairy technology. London: Elsevier, 1986. v. 1, p. 131-234.

KUMAR, C. G.; ANAND, S. K. Significance of microbial biofilms in food industry: a review. International Journal of Food Microbiology, v. 42, June, p. 9-27, 1998.

LELIEVELD, H. L. M.; MOSTER, M. A.; HOLAH, J. Handbook of hygiene control in the food industry. England: Woodhead Publishing, 2005. p. 720.

MELLO, C. A. Avaliação da eficiência de sanificantes químicos em condições de uso simulado sobre psicrotróficos acidificantes. Viçosa, 1997. 63 p. Dissertação (Mestrado em Ciência e Tecnologia de Alimentos). Universidade Federal de Viçosa - UFV.

MOSTELLER, T. M.; BISHOP, J. R. Sanitizer efficacy against attached bacteria in a milk biofilm. Journal Food Protection, v. 56, n. 1, p. 34-41, 1993.

SHARMA, M., ANAND, S. K. Bacterial biofilm on food contact surfaces: A review. Journal of Food Science \& Technology, v. 39, n. 6, p. 573-593, 2002.

STEWART, P. S. et al. Effect of catalase on hydrogen peroxide penetration into Pseudomonas aeruginosa biofilms. Applied and Environmental Microbiology, v. 66, February, p. 836-838, 2000

STONE, L. S.; ZOTTOLA, E. A. Relationship between the growth phase of Pseudomonas fragi and attachment to stainless steel. Journal of Food Science, v. 50, n. 4, p. 957-960, 1985.

ZOTTOLA, E. A.; SASAHARA, K. C. Microbial biofilms in the food processing: should they be a concern? International Journal of Food Microbiology, v. 23, n. 2, p. 125-148, 1994. 